\title{
An experimental approach to the ecological significance of microhabitat-scale movement in an encrusting sponge
}

\author{
Manuel Maldonado*, María J. Uriz \\ Dapartincat uf Aquaii Eluivyy, Ceniro de estudios Avanzados de Blanes (CSIC), Camino de Santa Barbara s/n, \\ E-17300 Blanes, Girona, Spain
}

\begin{abstract}
A few studies have shown that sponges are capable of locomotion on the substrata. However, the ecological significance of this ability remains virtually unexplored to date. Here, we conduct a series of experiments documenting the movement patterns of the encrusting sponge Scopalina lophyropoda as a function of food availability, density of neighbors, water flow, burial by silt, and body size. In all experiments, we used small sponges that were developed from explants after attachment to acetate sheets that served as substrata. The first experiment revealed that starvation is a powerful stimulus to locomotion, since starved sponges displaced over significantly greater distances than did fed sponges, irrespective of the density of neighbors. It was also found that paths were significantly more convoluted when sponges moved through high-density groups, irrespective of food availability. In a second experiment, we found that movement of an isolated sponge in the vicinity of barriers made of either histocompatible (isogeneic) or histoincompatible (allogeneic) conspecifics was not random, but was oriented significantly towards the neighboring barrier. Sponges were unable to determine neighbor compatibility before physical contact was made. In all isogeneic encounters, the outcome was tissue fusion. In contrast, all allogeneic encounters were characterized by an initial histological rejection and a subsequent change in path direction to avoid a situation of prolonged contact between sponges. In a third experiment, we found that sponges under conditions of dispersed flow with silt deposition traveled significantly further than sponges under directed flow without silt deposition. Direction of movement was random under conditions of dispersed flow, but sponges under conditions of directed flow moved perpendicularly to the flow direction, avoiding contact with the high-speed water jets. In a fourth field experiment, we assessed differences in mobility between relatively large and small individuals (i.e. in a size range equivalent to that of 1 yr old and 1 wk old postlarvae, respectively). Mobility was similar in both size ranges. The results of the experiments strongly suggest that sponges in the field may use the capability of locomotion to prevent prolonged physical contact with competitors and to move away from sites with limited access to food, or excessive exposure to silt and abrasion by water flows. The histological study revealed that moving sponges may incur certain costs, since both the canal system for water pumping and the skeleton responsible for the attachment of the sponge to the substratum have to be continuously reorganized as sponges move. Nevertheless, the selective (ecological) benefits derived from this ability must offset, or at least be in step with, histological and energetic costs. Were this not the case, sponges would not have evolved their capability of locomotion.
\end{abstract}

KEY WORDS: Sponge movement - Sponge behavior - Spatial competition - Microhabitat-scale behavior · Histocompatibility

\section{INTRODUCTION}

Sponges are successful organisms in most sublittoral and bathyal hard-bottom communities, where compe-

•E-mail: maldonado@ceab.csic.es tition for food and space is intense. They combine extreme anatomical simplicity with the ability to produce a large variety of bioactive metabolites which possess a potential ecological role (see reviews by Davis et al. 1989, Paul 1992, Pawlik 1993). This combination of traits has favored the idea that, chemically, 
sponges are effective competitor organisms, while behaviorally they are static and inert. The behavioral passiveness of sponges is a notion so entrenched in the literature that, for example, many relatively recent zoological treatises (e.g. Brusca \& Brusca 1990, Meglitsch \& Schram 1991, Ruppert \& Barnes 1994) still describe sponges as motionless animals. However, a number of studies dating back over a $50 \mathrm{yr}$ period provide evidence that many species are capable of movement across substrata. Edmundson (1946), Burton (1949) and Fishelson (1981) reported that small subspherical colonies of various species of the genus Tethya can move. Burton (1949) also reported movement of encrusting colonies of Hymeniacidon perleve and Halichondria panicea in both aquaria and intertidal rocky pools. Borojevic (1971) observed small displacements of the early juveniles of an unidentified species of Adocia and suggested that their movement was induced by high exposure to light. Wilkinson \& Vacelet (1979) described how 2 large, thick lamellate Chondrosia reniformis transplanted to artificial plates migrated 7 and $10 \mathrm{~cm}$, respectively, to the underside of the plates. These authors also reported small movements of fragmenting colonies of Chondrilla nucula. Newly settled sponges derived from both sexually and asexually produced propagules have also been reported to move erratically over short distances (e.g. Uriz 1982a, Battershill $\&$ Bergquist 1990). After documenting movement in 7 other sponge species belonging to 5 orders, Bond \& Harris (1988) concluded that locomotion is widespread in this phylum and that the mechanism of locomotion appears to be common to most species.

Using time lapse photography, Bond (1992) has shown that the displacement of most sponges is achieved by the cumulative crawling activity of the cells (basopinacocytes) that compose the sponge's lower surface (basopinacoderm). Formerly, Fishelson (1981) had described a different system of locomotion based on observations made in sponges of the genus Tethya, which may temporarily develop small podiumlike extensions provided with knobby ends. According to Fishelson, locomotion was achieved when the knots came into contact with the substratum, adhered to it, then shortened to pull the sponge body toward the podium attachment points. However, subsequent studies (i.e. Bond \& Harris 1988, Jones 1994) concluded that the processes which occurred in Tethya and other sponges are not involved in locomotion, but rather in feeding or asexual reproduction.

Irrespective of the mechanism, the ability to undergo active displacement, even if on small scales, may have major ecological implications. Locomotion may enable sponges to gain access to a panoply of potential ecological advantages which previously were thought to be inaccessible to these so-called sessile organisms. It was believed that survival of a sessile organism was dependent on the choice of settlement site made by the swimming larva, since subsequent relocation of the post-larva was impossible. Many studies have reported that settlement locations (even to differences that range from $\mu \mathrm{m}$ to $\mathrm{cm}$ ) may strongly determine postlarval survival (e.g. Gosselin \& Qian 1997, Hunt \& Scheibling 1997, Maldonado \& Uriz 1998). One can deduce that a locomotory capability enables a small sponge settled on an unfavorable site to move a short distance (on a scale of $\mathrm{mm}$ ) and thereby enhance its survival. Locomotion also enables an individual to readjust its position with relation to its neighbors. This ability may be crucial to species that show an aggregated distribution pattern, in which physical contact with neighbors is common. Sponge populations usually consist of a combination of both clonal individuals obtained from asexual reproduction and genetically distinci individuals derived from sexual processes (Jokiel et al. 1982, Jackson 1986, Tsurumi \& Reiswig 1997). Physical contact between clones (isogeneic encounter) usually involves tissue fusion and leads to an immediate increase in size. This size increase is thought to be advantageous because it may reduce the impact of mortality by partial damage, enhance performance in competition for space, and increase reproductive output by lowering the onset of the first reproduction (Jackson 1977, 1985, Grosberg \& Quinn 1986, Buss 1990, Rinkevich \& Weissman 1987). In contrast, contact between histoincompatible conspecific sponges (allogeneic encounter) may lead not only to intense immune rejection (e.g. Hildemann et al. 1979, Johnston \& Hildemann 1983, Neigel \& Avise 1983) but also to general ecological stress, because the individuals will compete for both space and food. Therefore, movement could play an important role in favoring or preventing encounters between conspecific neighbors.

Theoretically, there are a variety of ecological situations in which the locomotion would be highly advantageous. However, the potential ecological significance of this capability remains unexplored to date. This long-standing neglect not only hinders our understanding of the competition process in sponge-dominated communities, but also contributes to the erroneous idea that sponges are motionless. Here, we conduct an ecological assessment of movement in sponges, using Scopalina lophyropoda (Schmidt 1862). This is an encrusting sponge with an aggregated distribution (Uriz et al. 1998), the populations of which consist of a combination of both clonal individuals originating from the re-attachment of detached body fragments and genetically distinct individuals derived by sexual reproduction (Maldonado \& Uriz 1999). In a series of laboratory experiments using small sponge individuals, we document patterns of movement in 
response to food availability, density of conspecific neighbors, water flow, burial by silt and body size.

\section{METHODS}

General procedures. Scopalina lophyropoda (Demospongiae, Poecilosclerida) is an encrusting sponge found in many sublittoral Mediterranean communities, and is particularly abundant on the vertical sides of several submerged outcrops close to the Blanes coast $\left(2^{\circ} 48.12^{\prime} \mathrm{N}, 41^{\circ} 40.33^{\prime} \mathrm{E}\right)$, Spain, western Mediterranean (Uriz et al. 1998). For most experiments, we used small sponge individuals (1 to $2 \mathrm{~mm}^{2}$ ) obtained from explants, that is small tissue pieces torn from large specimens, which re-attach and develop into small functional sponges after a few days (Uriz 1982b). The regenerating power of body fragments is a wellknown mechanism of asexual reproduction among sponges (e.g. Simpson 1984, Wulff 1985, 1995).

In all experiments, sponge movement was assessed on an artificial substratum that consisted of a $0.3 \mathrm{~mm}$ thick, translucid acetate sheet. Sheets were treated with sandpaper to create a coarse-grained surface appropriate for sponge cell attachment. Once coarsened, each acetate sheet was sewn onto a transparent sheet, $0.1 \mathrm{~mm}$ thick bearing a printed grid (mesh = $1 \mathrm{~mm}$ ). This underlying sheet provided reference lines so as to trace sponge movement accurately. Prior to selecting acetate sheets as a substratum for the experiments, we observed that the small sponges were capable of movement on a large variety of substrata, such as ceramic tiles, clay tiles, acid-washed glass, coarsened plexiglass, polystyrene, coarsened acetate sheets and cobble pieces. We also noted that sponge motion did not differ substantially from one substratum type to another over a 2 wk period. Anyway, small differences in the motion rate would be irrelevant to the choice of a particular substratum, given that the primary objective was not to measure absolute motion but to assess differences in the rate of motion and movement patterns as a function of different ecological situations simulated in the laboratory. We finally chose acetate sheets as the experimental substratum because this material allowed us to fix a printed grid. In addition, this material can be easily coarsened to facilitate sponge cell attachment, cut effortlessly to fit within the different experimental bowls and aquaria, and processed successfully for additional transmission (TEM) and scanning electron (SEM) microscopy observation.

All substrata were washed in running seawater for at least 1 wk before being offered to explants for attachment. Movement was determined as the net displacement $( \pm 0.25 \mathrm{~mm})$ of the approximate center of mass of the sponge colony. Paths were digitized and treated for linear and angular measurements using SigmaScan software for Windows (Jandel Scientific Inc. 1993) and the public domain NIH Image program (U.S. National Institutes of Health, http://rsb.info.nih.gov/nih-image) on a Macintosh computer.

Movement in response to food availability and density of neighbors. To assess the potential effects of trophic and spatial competition on sponge movement, we exposed small sponges to a combination of 2 levels of food availability and 2 levels of conspecific density. For this experiment, we used a total of 10 glass bowls ( $19 \mathrm{~cm}$ in diameter $\times 15 \mathrm{~cm}$ in height) and 320 explants that were distributed randomly in 20 groups of 16 nieres Wo plared 2 groups of cuplante in cach glüss bowl, which had previously been filled with 1 l of $0.22 \mu \mathrm{m}$ filtered seawater and contained a gridded acetate sheet on the bottom to serve as substratum. One of the groups consisted of explants placed $0.5 \mathrm{~cm}$ apart, so that, after attachment and regeneration, we obtained a group of small sponges at relatively high density. The other group consisted of explants placed $2 \mathrm{~cm}$ apart, so that we obtained a group of sponges at relatively low density. From previous grafting experiments, we had determined that all sponges in a group would be histoincompatible (allogeneic), so that no fusion was possible between individuals making contact. Although we originally placed 16 explants per group, some tissue pieces failed to develop and the final number of functional sponges ranged between 12 and $16(14.9 \pm 0.25$, mean $\pm \mathrm{SE})$. Once explants developed into small sponges, we initiated food treatment. This consisted of the starvation of sponges contained in 5 bowls chosen at random and the feeding of the sponges in the remaining bowls. Bowls with the starved treatment were filled with an additional liter of $0.22 \mu \mathrm{m}$ filtered seawater, in which bacteria were virtually absent $\left(<1 \times 10^{2}\right.$ bacteria $\left.\mathrm{ml}^{-1}\right)$. In contrast, bowls with the fed treatment received an additional liter of $1.7 \mu \mathrm{m}$ filtered seawater supplemented with $5 \mathrm{ml}$ of a general culture of marine bacteria (40 to $60 \times$ $10^{6}$ bacteria $\mathrm{ml}^{-1}$ ). This bacterial culture was obtained by inoculating an autoclaved general medium for marine bacteria (i.e. $110.22 \mu \mathrm{m}$ filtered seawater, $5 \mathrm{~g}$ bacto-peptone and $5 \mathrm{~g}$ malt-extract) with $1 \mathrm{ml}$ of $4 \mu \mathrm{m}$ filtered seawater. The culture was maintained in the dark and renovated weekly. Sponges were reared for 2 mo, with weekly changes of water in all bowls and addition of bacterial food to feeding bowls. Food is unlikely to have been limiting in the bowls with the fed treatment at any time during the experiment, since density of bacteria immediately before a new water change ranged from $4 \times 10^{4}$ to $10 \times 10^{5}$ bacteria $\mathrm{ml}^{-1}$. These values are close to the monthly average of bacterial abundance in coastal waters of the area where the sponge population occurs (i.e. $1.3 \times 10^{5}$ to $9.8 \times$ 
$10^{5}$ bacteria $\mathrm{ml}^{-1}$; Vaqué 1996). Density of bacteria in cultures and treatment bowls was estimated by staining bacterial DNA with DAPI and using a HBO illuminator with a $100 \mathrm{~W}$ mercury lamp for fluorescence excitation in the near UV. Counts were made using a Weigel graticule inside the ocular of a Zeiss Axioplan microscope with a $100 \times$ oil immersion objective. Bowls were maintained in the laboratory at $22^{\circ} \mathrm{C}$, exposed to a $12 \mathrm{~h}$ light:12 h dark cycle of natural light screened through glass windows.

We measured the length and straightness of paths traced by sponges after 2 mo (February-March 1997) in the experimental conditions described above. To assess the extent to which the path traced by a sponge deviates from a straight line, we used the index of straightness (IS) proposed by Emlen \& Demong (1978):

$$
I S=D / W
$$

where $D$ is the distance from the starting to the end point and $W$ is the actual length of the path. Differences in both IS values and length of the paths traced by sponges after 2 mo as a function of food availability (fed vs starved groups), density of conspecifics (highdensity vs low-density sponge groups), and bowl ( 5 bowls for each level of food factor) were analyzed by 3-way nested analysis of variance (ANOVA). Because the sponges within a given bowl cannot simultaneously be starved and fed, the bowl factor was necessarily nested in the food factor. For the analysis of this nested design, we pooled the 'density $\times$ bowl' interaction into the error term, as suggested by Milliken \& Johnson (1984), and tested the significance of all 3 main effects and the second order interaction with potential biological meaning (i.e. food $x$ density). The ANOVA design would have been unbalanced because some explants failed to develop successfully into sponges $(12 \leq n \leq 16)$. However, to prevent the various problems related to the analysis of a 3 -way unbalanced nested design (i.e. uncertainty in the significance of the approximate tests, Sokal \& Rohlf 1981), we randomly eliminated some sponge individuals and obtained equal size groups $(n=12)$ so as to run a balanced ANOVA. A posteriori pairwise comparisons were made using the Student-Newman-Keuls (SNK) test. As the 3-way ANOVA revealed that bowl factor had no effect on either path length or path straightness, we only made a posteriori pairwise comparisons between the 4 groups from the 'food $x$ density' treatment combination. Untransformed straightness data were submitted to analysis, while distance data were ranked to meet the assumption of homoscedasticity (i.e. Cochran's test, $\mathrm{p}>0.05$ ).

To investigate variability in sponge movement over time, we recorded daily the distance that each sponge covered in the experimental treatments described above, then estimated the average speed ( $\left.\mathrm{mm} \mathrm{d}^{-1}\right)$ at which a sponge traveled during each week of the experiment. As previous analyses of variance had revealed that the bowl factor had no effect on sponge movement, we eliminated it from the analysis of speed. data to simplify the design. We collapsed the former 3 -way model (food $\times$ density $\times$ bowl) into a 2 -way model (food $x$ density) by grouping levels of food and density factors across levels of bowl factor. This procedure rendered a sample size of 60 sponges in each of the 4 'food $x$ density' combinations; however, we subsequently added a new third factor to the design (i.e. time factor). Despite the fact that sponge movement was monitored for a total of $8 \mathrm{wk}$, we only considered data from the first $5 \mathrm{wk}$, when most movement took place. Data from the last 3 wk were not only uninformative in terms of sponge motion, but also showed little or no variance (i.e. sponges covered small or no distances), violating severely both the homoscedasticity and normality assumptions of the ANOVA even after appropriate transformations. Thus, we finally analyzed differences in sponge speed as a function of food availability (fed vs starved groups), density of conspecifics (high-density vs low-density groups) and time (from Week 1 to Week 5). To avoid a design with repeated measures on factor time, the 60 sponge individuals resulting for each of the 4 'food $x$ density' combinations were assigned randomly to the 5 time groups ( $5 \mathrm{wk}$ ), making 12 individuals each. As a given individual provided speed data for just 1 of the $5 \mathrm{wk}$ considered in the analysis, speed measurements are independent over time. Differences in travelling speed $\left(\mathrm{mm} \mathrm{d}^{-1}\right)$ as a function of food availability, density of conspecifics and time were therefore analyzed by a standard 3-way ANOVA without repeated measures. Speed data were ranked prior to analysis. The SNK was used for a posteriori comparisons.

Oriented movement in the vicinity of conspecifics. We investigated whether proximity to allogeneic and isogeneic conspecifics induces directional movement responses. We reasoned here that, if sponges were somehow capable of perceiving the close occurrence of conspecifics before making physical contact with them (i.e. via waste discharges, expelled metabolites, pumping flows, etc), they would perform oriented displacements both to prevent allogeneic encounters and to favor those of an isogeneic nature. We simulated imminent allogeneic and isogeneic encounters in the laboratory by placing a small sponge (study subject) $2.5 \mathrm{~mm}$ in front of a semicircular barrier of conspecifics (Fig. 1). All neighboring barriers were made of 5 histocompatible sponges placed $2 \mathrm{~mm}$ apart. Barriers were either compatible (isogeneic) or incompatible (allogeneic) with the sponge individuals placed in front of them. The position ( $N, S, E$ or $W$ ) of the neighboring 


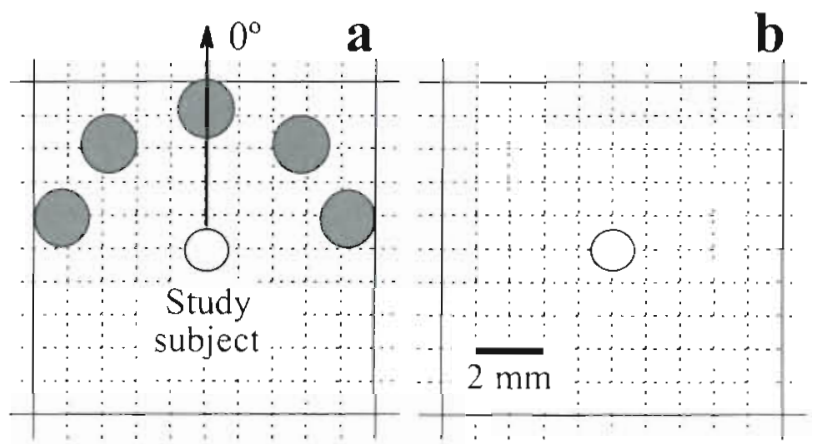

Fig. 1 Diagrammatic representation of the experimental setup to test for directionality in the displacement performed by isolated sponge individuals istudy suhiest) in the proscase of (a) a neighboring barrier made of either allogeneic or isogeneic conspecifics and (b) in the absence of neighbors (control). Barriers were oriented at random (N, S, E or W position) with respect to the study subject in each particular case. The line defined between the initial position of the sponge and center of the neighboring semicircular barrier of conspecifics served as angle $0^{\circ}$

barrier with respect to the isolated sponge was assigned randomly for each individual case. Isolated sponges with no neighboring barrier served as controls (Fig. 1). We studied a total of 30 cases of each encounter type (i.e. isogeneic, allogeneic or control) distributed randomly in 3 culture trays $(60 \times 40 \times 8 \mathrm{~cm})$ filled with $4 \mathrm{l}$ of $0.22 \mu \mathrm{m}$ filtered seawater and externally shielded with aluminum foil. During the experiment, sponges were starved and maintained in complete darkness to prevent potential effects of light gradients or food gradients on sponge orientation. The position of the sponges was recorded at $3 \mathrm{~d}$ intervals for $3 \mathrm{wk}$. Directionality in the movement responses was assessed by measuring the angle (from $0^{\circ}$ to $360^{\circ}$ ) that the mean vector of the path traced by a sponge formed with respect to the line defined between the initial position of the sponge and the center of the neighboring barrier, which served as angle $0^{\circ}$. We used circular statistics to describe and analyze these directional data (Mardia 1972, Batschelet 1981). The uniformity of data distribution was checked with the Rayleigh test, in which a significant $P$ value indicates that movements are not random, but directional within a particular treatment. As expected, control sponges moved randomly (Rayleigh test, $n=26, p=0.667$ ) with respect to a $0^{\circ}$ direction assigned randomly. Therefore, we dropped control sponges from subsequent comparisons of directionality and just examined differences in the preferred direction of movement between the sponges in allogeneic $(n=28)$ and isogeneic $(n=25)$ treatments. Differences were analyzed by the WatsonWilliam 2-sample test (Mardia 1972). The Watson's $F$-test for 2 circular means was not used because the concentration parameter of the angle data set was lower (e.g. $K_{\text {pooled }}=0.738$ ) than required for such tests. We calculated $95 \%$ confidence intervals (CI) for all significant mean vectors and used them to test whether an observed mean direction significantly differed from a predicted direction. An observed mean direction is considered to differ significantly from an expected direction if the latter lies outside the $95 \%$ CI for the observed mean (Batschelet 1981).

Movement in response to water flow and silt. To assess the effect of different hydrodynamic conditions, and silt deposition associated with these conditions, on sponge movement, we examined the movement resnonce of individuals ouposed to a disporscd, luvwvelocity flow and a directed, high-velocity flow. The former left a thin layer of silt on the substratum, while the latter did not leave any silt. The experiment was conducted using $0.75 \mathrm{~m}^{3}$ aquaria supplied with unfiltered, running seawater. The bottom of each aquarium was lined with a gridded acetate sheet bearing 2 parallel rows of 10 sponges each. Rows were $24 \mathrm{~cm}$ apart, while the individuals in each row were $2 \mathrm{~cm}$ apart. We placed a PVC horizontal tube $(\varnothing 3 \mathrm{~cm})$ between both sponge rows, and parallel to them. The tube was perforated by 10 holes $(\varnothing 2 \mathrm{~mm}, 2 \mathrm{~cm}$ apart) to allow the inflow of seawater (Fig. 2). Only sponges in the row on the drilled side of the tube were directly contacted by the incoming water jets. We characterized the seawater flow into the aquaria using fluorescein and confirmed that each jet was directed against a single

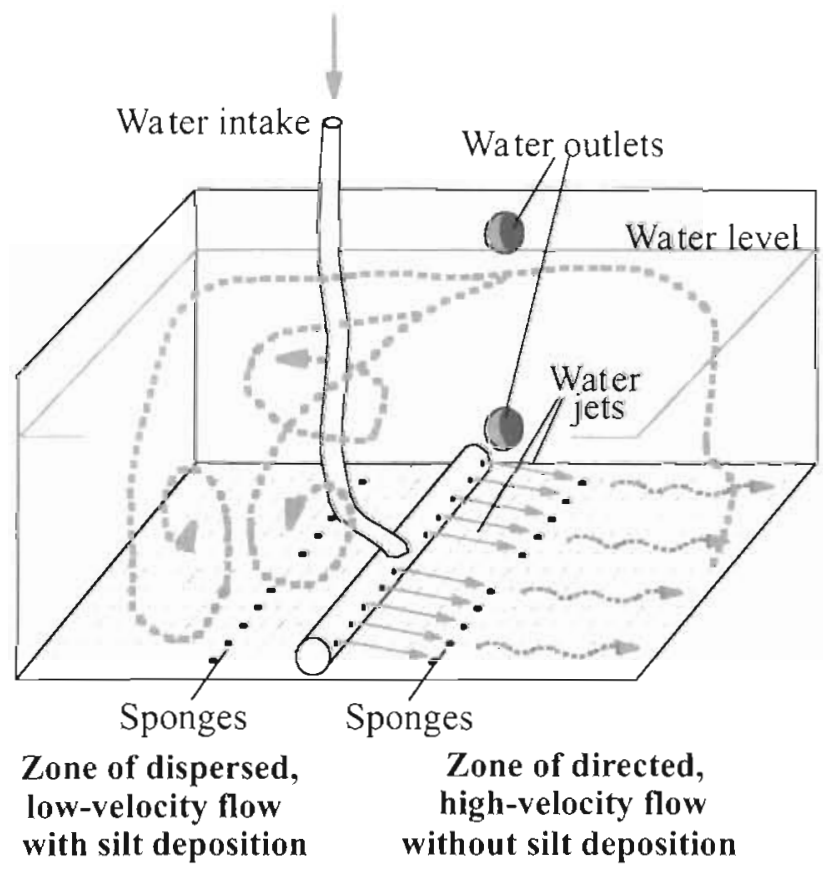

Fig. 2. Diagrammatic representation of the aquarium setup used to examine sponge movement patterns in response to flow-silt conditions 
sponge individual. Hence, all sponges in the row were similarly exposed to a high-velocity flow $(15$ to $20 \mathrm{~cm}$ $\mathrm{s}^{-1}$ ). Once these jets passed the sponge row and reached the wall of the aquarium, they coalesced into a current that flowed up and then back towards the other half of the aquarium (Fig. 2). Therefore, the sponges growing in this latter zone were exposed to a dispersed, low-velocity flow ( 2 to $5 \mathrm{~cm} \mathrm{~s}^{-1}$ ). Seawater was let out of the aquaria by 2 outlets open on the rear wall, one at the bottom and the other at the level of the water surface. That half of the aquarium bottom bathed by the dispersed, low-velocity flow accumulated silt at an approximate rate of $0.5 \mathrm{~mm} \mathrm{wk}^{-1}$, which was removed weekly. In contrast, the high velocity of the directed flow prevented any silt accumulation on the other half of the bottom. We monitored sponges weekly for $8 \mathrm{wk}$ and recorded the length, straightness and direction of paths with respect to prevailing flow directions, which served as angle $0^{\circ}$. The effects of flow and silt on the sponges were confounded in a single factor (hereafter referred to as flow-silt factor) in our experimental approach, as they are in the field. It is likely that sessile organisms that live on horizontal substrata exposed to high velocity flows or strong ambient currents are not under any danger of being buried, whereas those exposed to slow currents may be buried. We reasoned here that change in the exposure to silt would be responsible for differences in the intensity of the movement response (i.e. path length), while differences in the water flow would rather be responsible for differences in path straightness and directionality of sponge movement.

Differences in both length and straightness (IS) of paths as a function of aquarium factor ( 3 aquaria) and flow-silt factor (directed flow without silt deposition vs dispersed flow with silt deposition) were analyzed by a 2-way ANOVA. A posteriori comparisons were made using SNK tests. We also investigated temporal variability in the movement responses by examining differences in path length as a function of time. As the previous 2-way ANOVA revealed that aquarium factor had no significant effect on path length, we removed that spurious factor for this subsequent analysis, in which differences in path length as a function of flowsilt factor and time factor (first vs second mo of movement) were examined. Differences were first analyzed by a 2-way ANOVA with repeated measures on factor time. However, the assumption of circularity required for the analysis was violated (Mauchly's sphericity test). The multivariate equivalent approach of this test was not applicable either, since data did not meet the assumption of homogeneity of the variance-covariance matrix (Box M-test). Therefore, the repeated-measures distance data were finally analyzed by using a randomization approach (e.g. Manly 1991). The total be- tween- and within-subject sums of square (SS), as well as the overall total $S S$, remain unchanged after data randomization. Therefore, the SS associated with each factor and their interaction is a suitable statistic to test the significance of each effect. The randomization distribution of the SS for each factor and the interaction term (null hypothesis) was approximated by using 9999 random permutations of the data set plus the observed one. An effect was considered to be statistically significant when the observed sum of square values $\left(S S_{o b s}\right)$ was exceeded by less than $5 \%$ of the randomization sum of squares values $\left(S S_{\text {ran }}\right)$. Randomization analyses were performed using a computer routine in Turbo Pascal v6.0 (see Turon et al. 1998).

To describe and analyze directionality in the response movement with respect to the prevailing flow direction (i.e. angle $0^{\circ}$ ), we used circular statistics. Again, we discarded the spurious aquarium factor by pooling direction data within each level of the flow-silt factor across aquaria. As some explants failed to develop, we finally analyzed data from a total of 26 sponges under conditions of directed flow and no silt and a total of 28 individuals under conditions of dispersed flow and silt. The uniformity of data distribution in each level of the flow-silt treatment was checked with the Rayleigh test (Mardia 1972). We could not assess differences between non-significant mean directions. A $95 \%$ CI was calculated for all significant means and this was used to test whether the observed mean direction significantly differed from a prevailing flow direction. In the case of directed flow, we also examined the possibility that paths traced by sponges avoided the prevailing direction of flow, thereby originating a diametrically bimodal distribution of orientation data along a diameter line defined by the flow direction (oriented at $0^{\circ}$ ). Mean angles and $95 \% \mathrm{Cl}$ of data sets suspected to be bimodally distributed were calculated according to Zar (1984) and used to test whether or not the observed mean direction significantly differed from $90^{\circ}$, which is a direction perpendicular to the prevailing flow.

Locomotion as a function of body size. To assess the role of body size on the capability of locomotion, we compared the distance covered by small sponges and large sponges after $1 \mathrm{mo}$. The size of the small sponges $\left(1.8 \pm 0.7 \mathrm{~mm}^{2}\right)$ originated from explants was equivalent to that of a juvenile sponge just a few days after larval settlement, and the size of large individuals $\left(15 \pm 4.5 \mathrm{~mm}^{2}\right)$ approximately corresponded to that of 1 yr old sponges. Sponge size (area) was determined through a dissecting microscope connected to an integrated image analysis system using NIH Image software. For the experiment, a total of 70 large and 70 small sponges were distributed at random on 10 gridded acetate sheets, which were taken to the field and 
suspended vertically at depths of between 8 and $12 \mathrm{~m}$ from screws pre-installed at random in the rocky walls. Sponges were monitored weekly and their displacement measured in situ on the gridded acetate sheet, according to the technique explained in the 'General procedures' section. Differences in distance covered $( \pm 0.25 \mathrm{~mm})$ by those small and large individuals that survived $\left(n_{5 m a l l}=56, n_{\text {large }}=40\right)$ after a month were analyzed using a $t$-test .

Histological and time-lapse behavioral observations. For TEM study of the basal pinacoderm, we fixed sponges attached to acetate sheets in glutaraldehyde $2.5 \%$ buffered with $0.4 \mathrm{M}$ cacodylate in seawater (4 vol.:5 vol.), post-fixed in $2 \%$ osmium tetroxide. dehydrated through a graded ethanol series, and included in ERL 4206 (according to Spurr 1969). Ultrathin sections were stained with uranyl acetate and lead citrate and examined in a Philis EM-301 electron microscope. For SEM study, sponges attached to acetate sheets were fixed in a mixture of osmium tetroxide $2 \%$ and a saturated solution of mercuric chloride 6 vol.: 1 vol.), dehydrated in an ethanol series, fractured in liquid nitrogen, dried to critical point, sputter-coated with gold, and examined in a Hitachi S-2300 electron microscope. Additional behavioral observations on moving sponges were carried out using a time-lapse video recorder (JV BR-S920E) connected to a video camera (JVC TK-C1381) mounted on a Wild-M10 compound microscope.

\section{RESULTS}

\section{Movement in response to food availability and density of neighbors}

A total of 298 out of 320 explants successfully developed into sponges. Over $99 \%$ of the sponges moved away from the initial attachment point, covering distances that ranged from 0.25 to $18 \mathrm{~mm}$ after $2 \mathrm{mo}$ in the experimental bowls. An ANOVA (based on data from 240 sponges taken randomly among the 298 surviving individuals) and a posteriori comparisons revealed that starved sponges traced longer paths $(7.05 \pm 0.33 \mathrm{~mm})$ than fed sponges $(4.09 \pm 0.20 \mathrm{~mm})$, irrespective of the density of conspecifics and culture bowl (Figs. 3a,c \& 4, Table 1). Nevertheless, sponges in high-density groups traced more convoluted paths (i.e. with a significantly lower IS value) than sponges in low-density groups, and irrespective of food availability and culture bowl (Fig. 3b,d, Table 1). In all cases in which 2 individuals made contact, motion ceased for a few days ( 1 to $8 \mathrm{~d}$ ). Sponges shrank and became denser as result of a mild immune response. Then, 1 or both individuals resumed movement at high speed, following divergent or op-

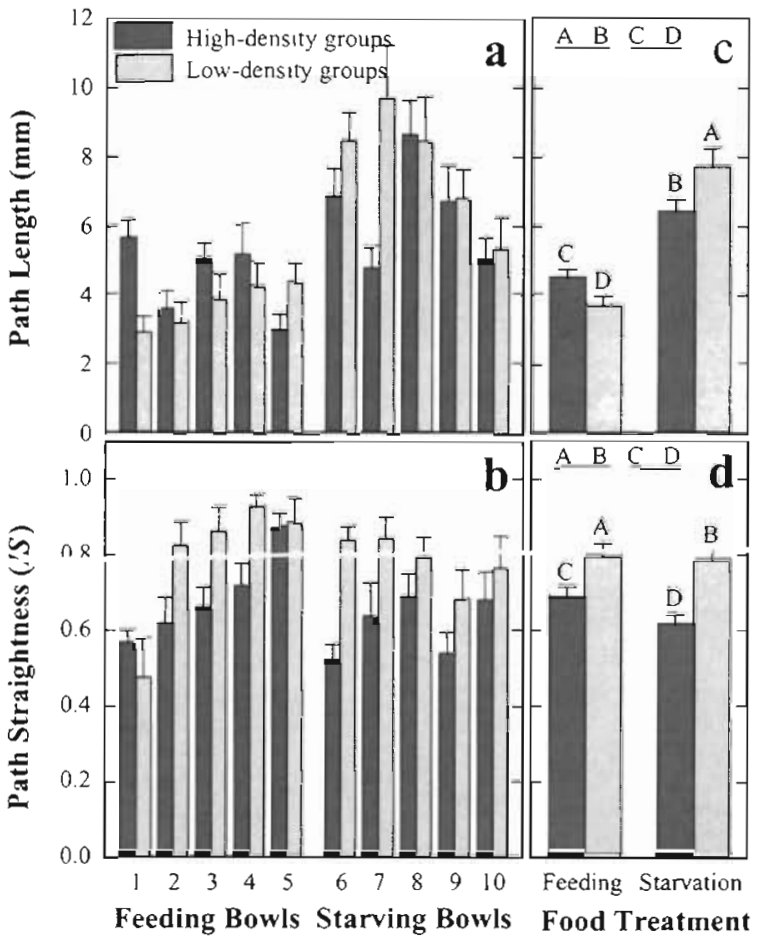

Fig. 3. $(a, b)$ Mean $( \pm S E)$ length and straightness (IS) of paths traced by sponges after 2 mo in culture bowls as a function of food availability (fed vs starved sponges), density of conspecifics (high-density vs low-density groups) and culture bowl ( 5 bowls per each level of food factor). (c,d) Mean ( \pm SE) length and straightness (IS) of paths after pooling data across levels of the spurious bowl factor, then considering only the sponge groups resulting from the combination of food and density factors. Letters (A. to D) indicate mean values arranged in descending order. Groups of underlined letters indicate non-significant differences between pairs of means according to a posteriori SNK tests $(\mathrm{p}>0.05)$ following an ANOVA (see Table 1)

Table 1. Results of 3-way nested ANOVAs on length (ranked data) and straightness (IS) of paths traced by sponges after $2 \mathrm{mo}$ as a function of food availability (starved vs fed sponges), density of conspecific neighbors (high-density vs low-density groups) and culture bowl ( 2 groups of 5 bowls). Bowl factor is nested in food factor in both analyses. "Statistically significant effects at the $99 \%$ confidence levels. A posteriori comparisons are given in Fig. 3

\begin{tabular}{|lrrrc|}
\hline Source & df & \multicolumn{1}{c}{ MS } & $F$ & $p$ \\
\hline Path length & & & & \\
Food & 1 & 199411.3 & 25.642 & $<0.001 \cdots$ \\
Density & 1 & 24.7 & 0.003 & 0.956 \\
Bowl & 8 & 8016.0 & 1.030 & 0.483 \\
Food $\times$ Density & 1 & 20038.5 & 2.576 & 0.147 \\
Error & 8 & 7776.6 & & \\
Path straightness $(I S)$ & & & & \\
Food & 1 & 0.110 & 1.300 & 0.287 \\
Density & 1 & 1.160 & 13.666 & $0.006 \cdots$ \\
Bowl & 8 & 0.261 & 3.082 & 0.065 \\
Food $\times$ Density & 1 & 0.060 & 0.714 & 0.422 \\
Error & 8 & 0.085 & & \\
& & & & \\
\end{tabular}




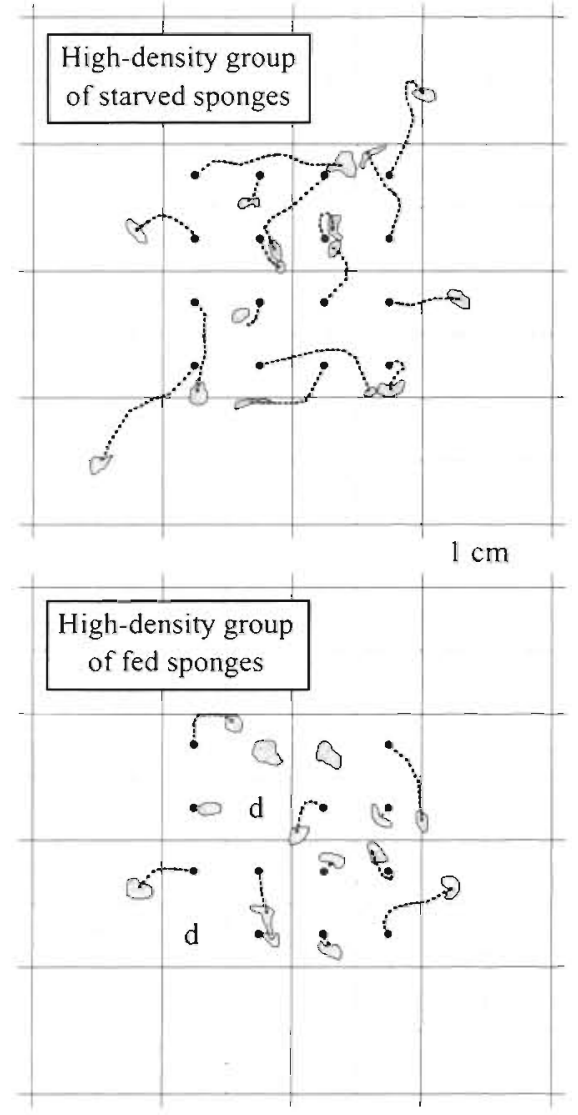

Fig. 4. An example of paths traced by fed and starved sponges arranged in high density. Dotted lines indicate the course of paths traced after 2 mo in bowl cultures. d: empty quadrats owing to unsuccessful (dead) explants

posite directions to avoid a situation of prolonged physical contact and a subsequent re-encounter. This behavior was consistently repeated in subsequent contacts with other neighbors in the group. The higher rate of encounters in high density-groups than that in a low-density situation forced sponges to change the direction of movement very often to elude prolonged contacts, and it accounted for the lower IS value of paths traced in the high-density groups.

The shape of the motion curves over time (considering either cumulative distance covered per week or daily speed within a given week) indicated that the most substantial displacements were performed over the first $3 \mathrm{wk}$, with peaks of movement during the second week for fed sponges and during the third for starved sponges (Fig. 5). Individual speed ranged from 0 to $1.178 \mathrm{~mm} \mathrm{~d}^{-1}$ (data from all surviving sponges pooled), depending on the particular treatment combination and time period. A 3-way ANOVA on speed of movement from 240 sponges taken randomly among the 298 surviving individuals revealed differences in speed as a function of food and time factors, irrespective of the density of conspecifics (Table 2). A posteriori comparisons confirmed that starved sponges moved significantly faster than fed sponges (SNK test, p < 0.05), irrespective of density treatment. The analysis also confirmed that speed of movement was high during the first 3 wk (SNK test, pairwise $p>0.05$ ), decreasing significantly during subsequent weeks ( $\mathrm{p}<$ 0.05). The ANOVA detected a significant interaction between density and time factors. This interaction is apparent (Fig. 5), in part, because the sponges of the high-density groups moved faster than those of the low-density groups during just the first week of the experiment (SNK tests, $p<0.05$ ), and irrespective of food availability. In contrast, starved sponges moved significantly faster than fed sponges during Weeks 3 and 4 (SNK tests, $p<0.05$ ), irrespective of the density

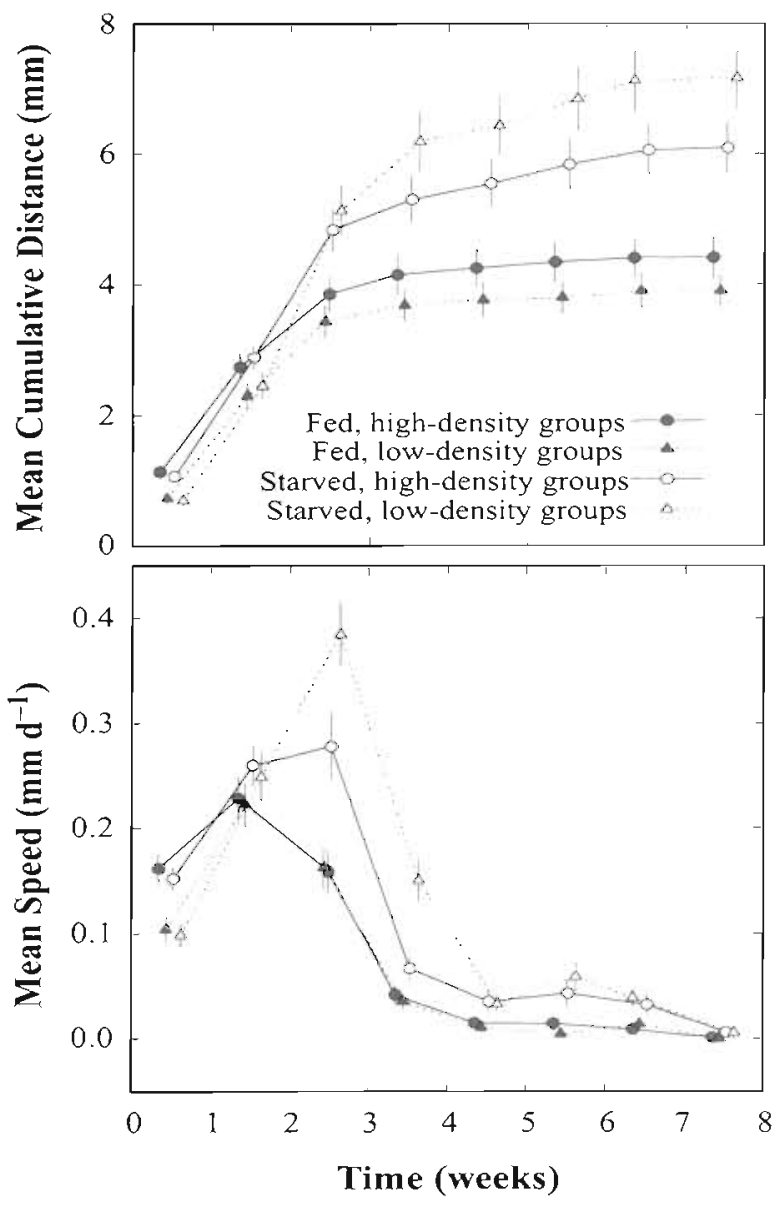

Fig. 5. Cumulative mean distance ( $\pm \mathrm{SE}$ ) covered weekly by sponges and mean weekly speed $( \pm S E$ ) as a function of food availability (fed vs starved sponges) and density of conspecifics (high vs low density) over time ( $8 \mathrm{wk}$ ). Distance and speed data are from all 298 sponges that survived for 2 mo in culture bowls. See Table 2 for a statistical analysis of differences in speed (on data from 240 individuals taken randomly) as a function of food, density of conspecifics and time factors 
Table 2. Results of a 3-way ANOVA on sponge traveling speed ( $\mathrm{mm} \mathrm{d}^{-1}$, ranked data) as a function of food availability (starved vs fed sponges), density of conspecific neighbors (high-density vs low-density groups) and time ( $5 \mathrm{wk}$ ). Statistically significant effects at the $95\left({ }^{\circ}\right)$ and $99 \%\left({ }^{\prime}\right)$ confidence levels are indicated

\begin{tabular}{|lrrrc|}
\hline Source & df & MS & $F$ & $p$ \\
\hline Food & 1 & 14742.3 & 4.899 & $0.027^{\circ}$ \\
Density & 1 & 64.0 & 0.021 & 0.884 \\
Time & 4 & 86454.8 & 28.730 & $<0.001 \cdots$ \\
Food $\times$ Density & 1 & 246.5 & 0.081 & 0.775 \\
Food $\times$ Time & 4 & 4591.4 & 1.525 & 0.195 \\
Density $\times$ Time & 4 & 11580.8 & 3.848 & $0.004 \cdots$ \\
Food $\times$ Density $\times$ Time & 4 & 2700.3 & 0.897 & 0.466 \\
Error & 220 & 3009.1 & & \\
& & & & \\
\hline
\end{tabular}

of conspecifics. A subsequent 2-way ANOVA (density $\times$ time) blocking time factor confirmed a significant 'density $\times$ time' interaction. Similarly, a posteriori SNK tests $(p<0.05)$ confirmed that sponges moved significantly faster within the high-density groups compared to the low-density groups during Week 1, while this pattern was reversed during Week 3.

\section{Oriented movement in the vicinity of conspecifics}

Sponges moved with a significant directionality in the vicinity of both allogeneic (Rayleigh test, $p=0.011$ ) and isogeneic ( $p=0$.002) neighboring barriers, while control sponges moved at random ( $p=0.667$ ), as expected. The mean direction $( \pm 95 \% \mathrm{CI})$ of paths traced by sponges was $34.949^{\circ} \pm 36.419^{\circ}$ in the allogeneic treatment and $344.551^{\circ} \pm 41.606^{\circ}$ in the isogeneic treatment (Fig. 6). A 2-sample test detected no significant difference in mean direction $\left(R^{\prime}=0.397, \mathrm{p}>0.05\right)$ between isogeneic and allogeneic treatments. In both cases, sponges moved with a mean direction that was not significantly different from $0^{\circ}$, showing oriented displacement towards neighboring barriers. Sponges made contact with isogeneic barriers in $72 \%$ of cases, and with allogeneic barriers in $53.57 \%$ of cases. In all cases of isogeneic contact, the outcome was tissue fusion. In contrast, all allogeneic encounters were characterized because locomotion ceased for a few days after contact ( 1 to $8 \mathrm{~d}$ ) and individuals showed mutual tissue rejection, with formation of a stand-off edge along contacting zones. Then, movement was resumed in reverse or divergent direction, avoiding a situation of prolonged physical contact. This 'stop-andreverse' behavior was successively repeated whenever individuals became involved in subsequent allogeneic encounters.
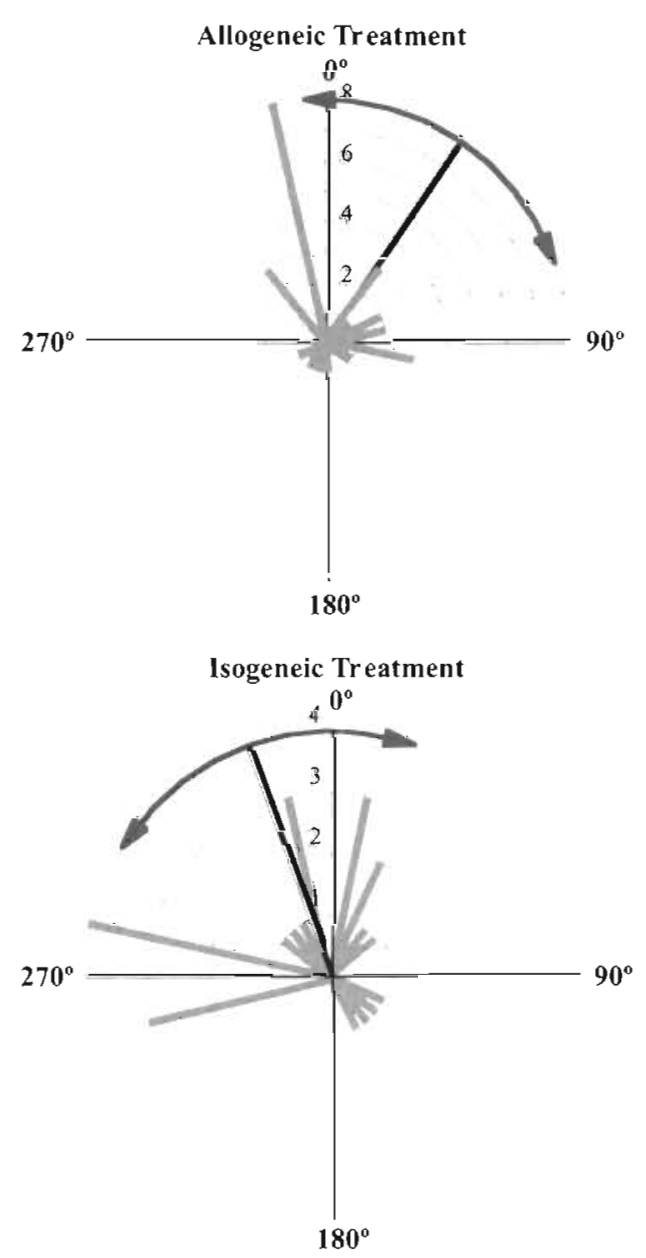

Fig. 6. Circular histograms showing directions of movements performed by sponges with respect to the line defined between the initial position of the sponge and the center of the neighboring semicircular barrier of conspecifics, which served as angle $0^{\circ}$. Directions are grouped in $15^{\circ}$ bars. Mean directions and $95 \% \mathrm{CI}$ are indicated by a black line and a double-headed arrow, respectively

\section{Movement in response to water flow and silt}

All sponges reared in running-seawater aquaria moved from the initial attachment point, covering a total distance that ranged from 16.1 to $63.7 \mathrm{~mm}$ after 2 mo (Fig. 7), at a mean speed ( \pm SE) of $0.65 \pm 0.03 \mathrm{~mm}$ $\mathrm{d}^{-1}$ (all data pooled). An ANOVA and its a posteriori comparisons revealed that sponges traced significantly longer paths (mean distance $\pm \mathrm{SE}$ ) under conditions of dispersed flow and heavy siltation $(43.5 \pm 2.7 \mathrm{~mm})$ than under conditions of directed flow and no silt ( 34.8 $\pm 3.0 \mathrm{~mm}$ ), and irrespective of the aquarium factor (Table 3). The randomization analysis of distance data with repeated measures on the time factor also indicated that sponges traced longer paths in conditions of dispersed flow and silt deposition compared to condi- 


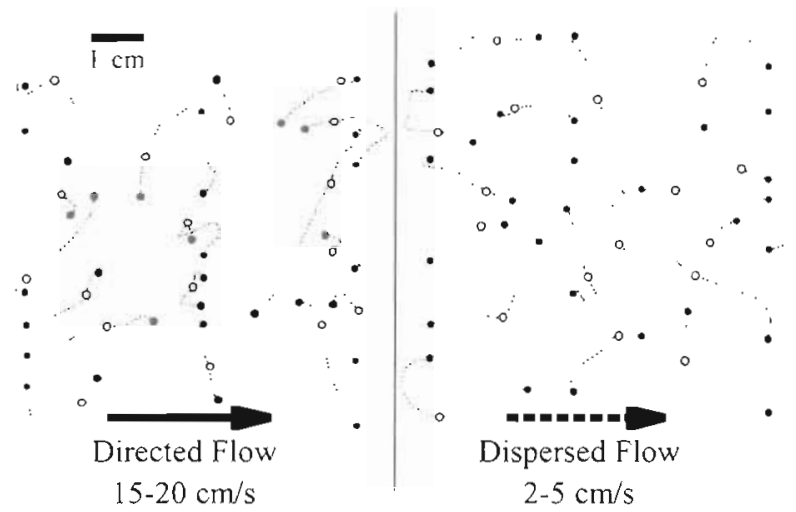

Fig. 7. A few examples of paths traced by both sponges exposed to a directed, high-velocity flow that did not leave any silt on the substratum and sponges exposed to a dispersed, low-velocity flow that left a silt layer on the substratum. Black, white and gray circles indicate the position of the moving sponges at the beginning, after 1 mo and after 2 mo in the aquaria, respectively. Dotted lines indicate the course of displacement with respect to the prevailing flow direction, which is shown by the arrows at the bottom

tions of directed flow and no silt, and that distances covered during the first month were larger than during the second month (Fig. 8, Table 4). Nevertheless, a. significant interaction term revealed that the effect of siltation on sponge movement was limited to the first month, so that the role of siltation in inducing movement decreased with increasing time (Fig. 8, Table 4). The ANOVA on IS data detected no significant difference in path straightness as a function of the aquarium factor or the flow-silt factor (Table 3).

Directional data revealed that, although sponges exposed to a dispersed flow showed an apparent trend to move in the opposite direction (mean $\pm 95 \% \mathrm{Cl}=$ $214.7^{\circ} \pm 47.8^{\circ}$ ) to the prevailing water direction (Fig. 9), movement in both experimental flow conditions lacked any statistically significant directionality (Rayleigh

Table 3. Results of 2-way ANOVAs on length (mm) and straightness (IS) of paths traced by sponges for 2 mo as a function of flow-silt factor (directed flow and no silt vs dispersed flow and silt deposition) and aquarium factor ( 3 aquaria). - Statistically significant effects at the $95 \%$ confidence level

\begin{tabular}{|lrrcc|}
\hline Source & df & MS & $F$ & $\mathrm{p}$ \\
\hline $\begin{array}{l}\text { Path length } \\
\text { Aquaria }\end{array}$ & 2 & 76.5 & 0.523 & 0.596 \\
$\begin{array}{l}\text { Flow-Silt } \\
\text { Aquaria } \times \text { Flow-Silt }\end{array}$ & 1 & 1007.7 & 6.886 & $0.011^{*}$ \\
Error & 53 & 67.3 & 0.460 & 0.634 \\
Path straightness (IS) & & & & \\
Aquaria & 2 & 0.020 & 0.835 & 0.440 \\
Flow-Silt & 1 & 0.021 & 0.895 & 0.348 \\
Aquaria $\times$ Flow-Silt & 2 & 0.072 & 1.523 & 0.228 \\
Error & 53 & 0.024 & & \\
\hline
\end{tabular}

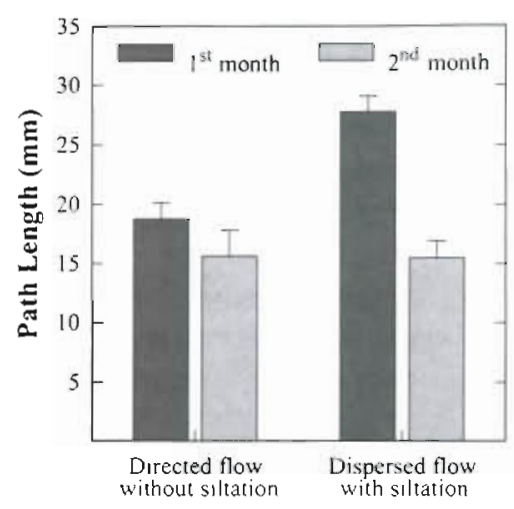

Flow-Silt Treatment

Fig. 8. Monthly mean length $( \pm \mathrm{SE})$ of paths traced by sponges exposed to both a dispersed flow with silt deposition and a directed flow without silt deposition for 2 mo. See Table 4 for a statistical analysis of data

test; $\mathrm{p}=0.071$ under dispersed flow, $\mathrm{p}=0.990$ under directed flow). Directionality of sponge movement under conditions of directed flow was so low that a $95 \%$ CI for the mean could not be calculated. Rather, this data set appears to follow a distribution that has 2 modes lying opposite each other and perpendicular to the prevailing flow direction, as shown in Fig. 9. A statistical analysis of such data under a bimodal distribution model revealed that mean direction $( \pm 95 \% \mathrm{CI})$ of sponge movement was $77.5^{\circ} \pm 44.1^{\circ}$, meaning that the bimodal distribution lies along a diameter line oriented at $77.5^{\circ}$, which is nearly perpendicular to the flow direction.

\section{Locomotion as a function of body size}

Mean distances $( \pm \mathrm{SE})$ covered after 1 mo by small and large sponges that survived in the field were $13.5 \pm 1.1 \mathrm{~mm}$ and $14.7 \pm 1.4 \mathrm{~mm}$, respectively, with a corresponding maximum distance of 37 and $33 \mathrm{~mm}$.

Table 4. Results of the randomization analysis for the repeated measures of path length (mm). Factors are flow-silt (directed flow and no silt vs cispersed flow and silt) and time (Month 1 vs Month 2), with repeated measures on time factor The $S S_{\text {ran }}>S S_{\text {obs }}$ column contains the percentage of randomization sum of squares $\left(S S_{\mathrm{ran}}\right)$ that exceed observed sum of squares $\left(S S_{o b s}\right)$ for each factor and their interaction. Statistically significant effects at the $95\left(^{\circ}\right)$ and $99 \%\left("{ }^{\prime}\right)$ confidence levels are indicated

\begin{tabular}{|lc|}
\hline Source & $S S_{\text {rdn }}>S S_{\text {obs }}$ \\
\hline Flow-Silt & $<0.001 . \cdot$ \\
Time & $0.009^{\circ}$ \\
Flow-Silt $\times$ Time & $0.029^{\circ}$ \\
\hline
\end{tabular}




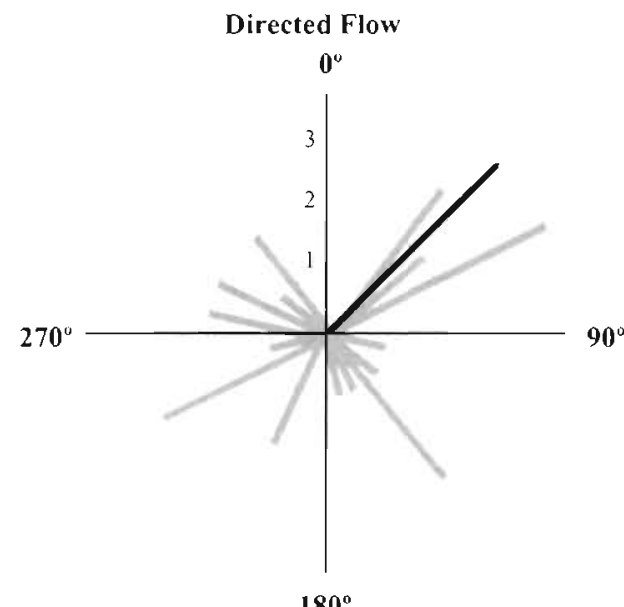

$180^{\circ}$

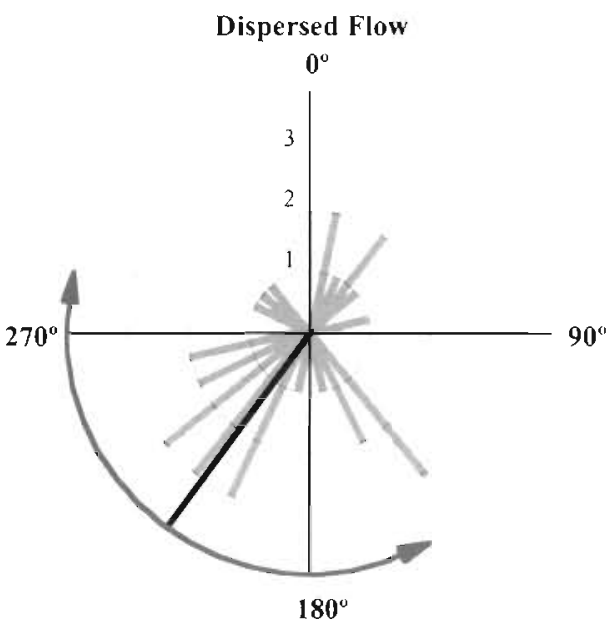

Fig. 9. Circular histograms showing directions of displacements performed by sponges with respect to the prevailing flow direction (angle $0^{\circ}$ ) in conditions of both directed, highvelocity flow and dispersed, low-velocity flow. Directions are grouped in $15^{\circ}$ bars. Mean directions and $95 \% \mathrm{CI}$ are indicated by a black line and a double-headed arrow, respectively. The high dispersion of movement data in conditions of directed flow did not allow the calculation of a $95 \% \mathrm{Cl}$ for the mean direction. See 'Results' for tests under a bimodal distribution

There was no significant difference between mean distances covered by small and large sponges ( $t$-test, $n_{\text {small }}$ $=56, \mathrm{n}_{\text {large }}=40, t=0.346, \mathrm{p}=0.729$ ).

\section{Histological and time-lapse behavioral observations}

Moving sponges showed both a well-developed skeleton and a functional aquiferous system. Timelapse photography through a dissecting microscope revealed that at least part of the canal system for water filtering was continuously reorganized as sponges moved. Reorganization was necessary because cell masses in different body parts migrated at different speeds, with cells in the lateral and the leading margin usually moving faster than cells in the remaining parts of the body. This asynchrony also provoked a continuous reshaping of the moving sponges, which were nearly circular when inert. We found 2 different morphologies typically associated with locomotion. Individuals that were initiating or ending a period of movement adopted an ellipsoidal form, with the wider end directed forward (Fig. 10A). In contrast, during periods of maximum motion rate, moving individuals adopted an arc form with a convex leading margin and a concave receding margin (Fig. 10B). These arc-shaped forms showed a somewhat disorganized choanosome compared th ollincnidal forms, ryhich wavily shovicu a well-developed canal system for water filtration.

It is also noteworthy that moving sponges secreted a 'normal' basal skeleton, which consists of vertical spicules (styles) anchored to the substratum by patches of spongin. This skeleton is responsible for the firm attachment of the sponge to the substratum when static (Fig. 11A,B). Part of this skeleton was consistently left behind, as sponges moved along (Fig. 11B,C). TEM observations confirmed that sponges secrete a collagen layer (basal spongin) between the basal cell layer (basopinacoderm) and the substratum (Fig. 12A,B), regardless of whether they are in motion or at rest. SEM and TEM observations of basopinacocytes of both moving and motionless sponge individuals did not reveal any striking difference. Basopinacocytes formed a single layer, with cells joined by interdigitating junctions, as is usual in other pinacoderms. The only histological difference observed between sponges in motion and those in motionless periods was the abundance of needle-shaped, isolated archeocytes near the basopinacoderm of moving sponges.

The organic part of the skeleton (spongin) that is left behind as sponges move favored a dark-colored bacterial colonization of pathways traced by sponges in some long-term laboratory cultures (Fig. 10C). When bacteria colonized paths traced by sponges that had been reared in the laboratory with an irregular alternation of starvation and feeding periods for $7 \mathrm{mo}$, an alternation of motion and resting periods was apparent along the tracks, probably in response to food availability. Resting periods were marked by wider, circular spots along the track, reflecting either expansion or growth of the motionless sponge body (Fig. 10C).

\section{DISCUSSION}

\section{Magnitude and mechanics of displacement}

Our results confirmed that the sponge Scopalina lophyropoda is capable of locomotion across substrata. 

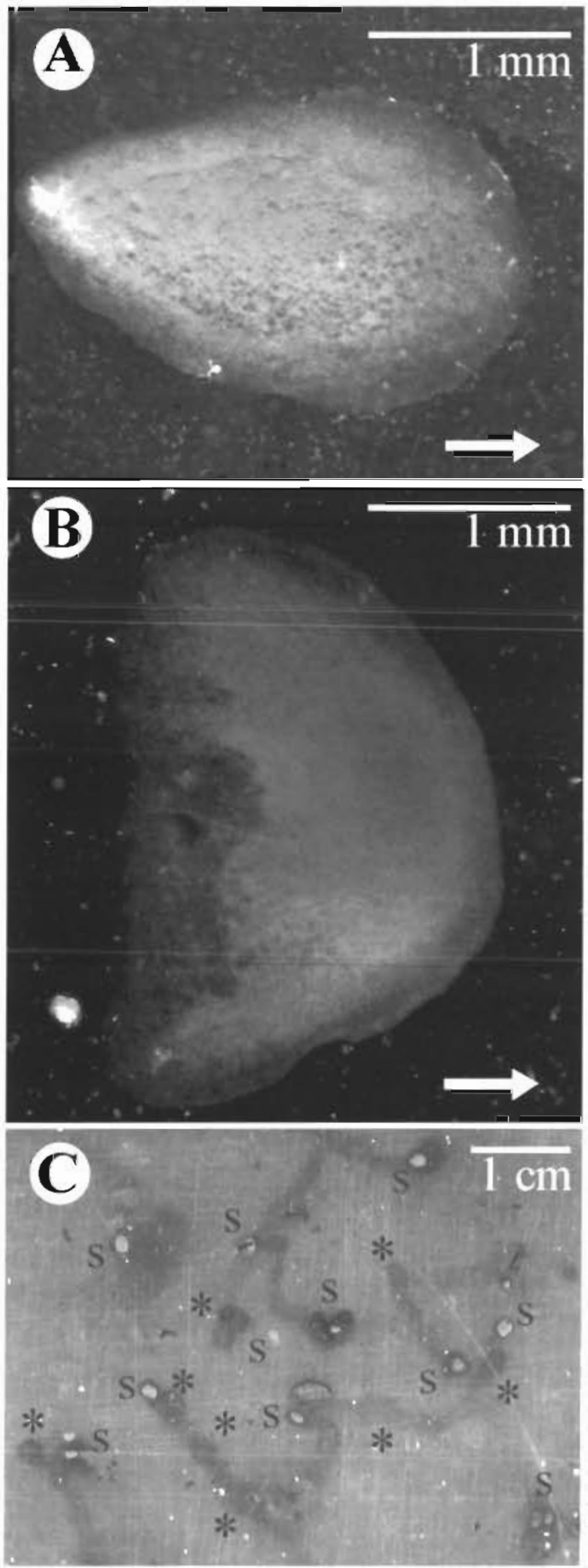

Fig. 10. (A) Morphology adopted by sponges when traveling at slow speed. The well-developed aquiferous system has to be continuously reorganized as the sponge moves. (B) Morphology adopted by sponges when traveling at maximum speed. Note that the aquiferous system is already somewhat disorganized and it will have to be reorganized when the sponge slows down. Arrows in (A) \& (B) indicate displacement direction. (C) Paths traced by pairs of allogeneic sponges (s) that were initially in contact. Circular thickenings in the tracks $(*)$ revealed that sponges alternated movement and resting periods during this 7 mo displacement
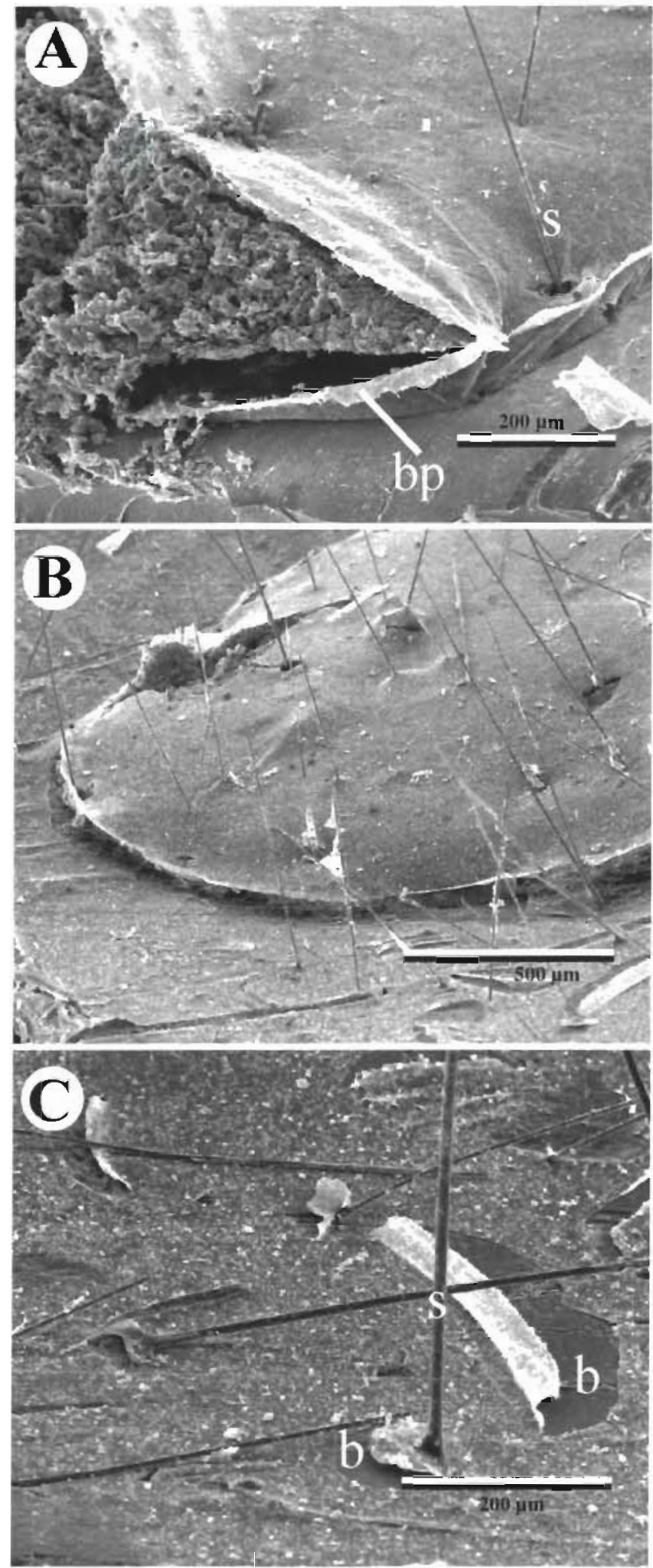

Fig. 1.1. SEM micrographs showing (A) that the pinacocytes from the upper and basal ectosomal layers of the sponge form indistinguishable mono-layered cell sheets, both protruded by a spicule (S), (B) part of the basal skeleton left behind by a moving sponge, and (C) detail of the left skeleton which consisted of silica spicules (s) attached by basal spongin patches (b) 


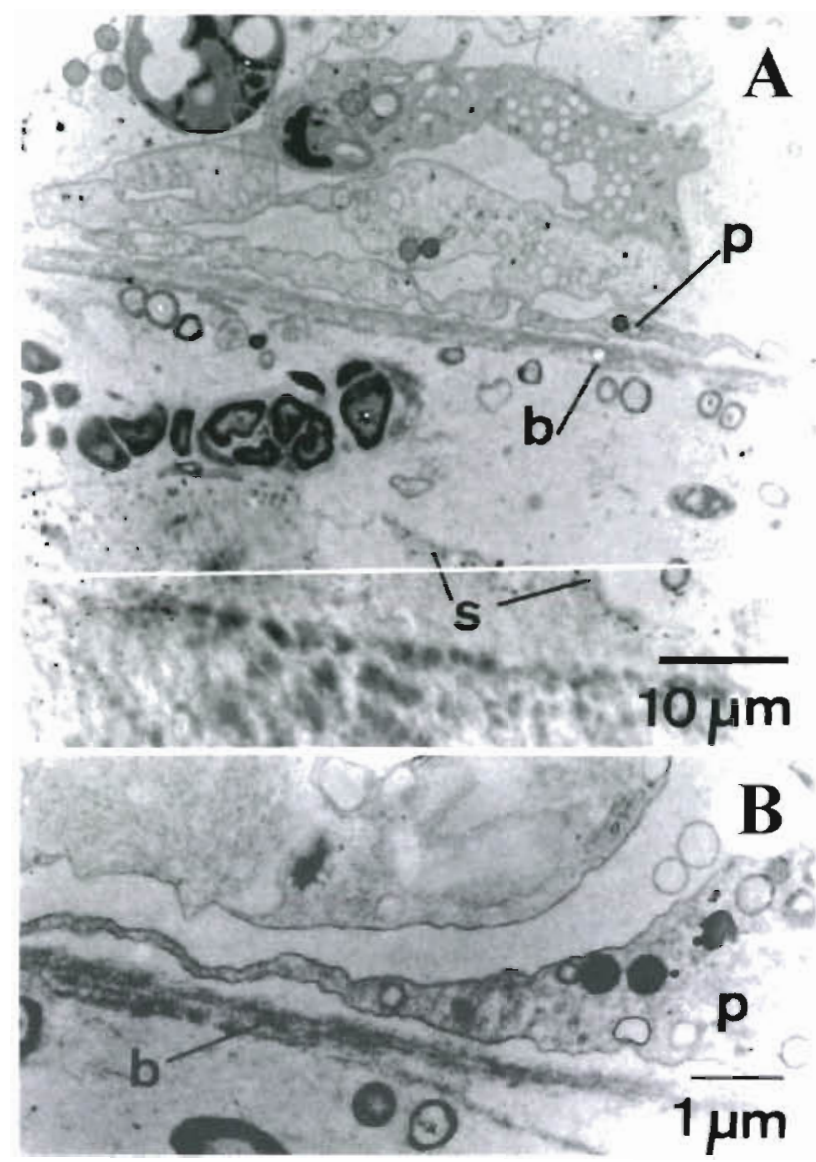

Fig. 12. TEM micrograph(A) showing (A) that the basopinacoderm (p) and the substratum surface (s) are connected throughout a lax matrix of collagen that differentiates into a narrow spongin layer (b) just below the pinacocytes. The matrix of collagen is colonized by abundant bacteria. (B) Detail of a basopinacocyte (p) and the basal spongin layer (b)

Displacements onto acetate sheets ranged from 0.5 to $37 \mathrm{~mm}$ when sponges were taken to the field for $1 \mathrm{mo}$, from 0.25 to $18 \mathrm{~mm}$ when sponges were reared in glass bowls for $2 \mathrm{mo}$, and from 16.1 to $63.7 \mathrm{~mm}$ when sponges were cultured in running-seawater aquaria for the same period. A displacement of $63.7 \mathrm{~mm}$ after 2 mo in aquaria means transporting the sponge body $\left(1.7 \mathrm{~mm}^{2}\right.$ on average) about 37 times its length during that time. Casual observations suggest that net displacements of large sponges may be greater in the field. For example, Burton (1949) reported that some Tethya colonies covered $30 \mathrm{~cm}$ in $5 \mathrm{mo}$, and Wilkinson \& Vacelet (1979) mentioned that a large Chondrosia reniformis moved $7 \mathrm{~cm}$ in $16 \mathrm{wk}$. Therefore, values of net displacement on the acetate substrata are neither comparable between experiments nor probably very representative of the magnitude of potential displacements on natural substrata in the field. Nevertheless, the present study, although affected by the limitations of a laboratory approach, still provides some insights into the determinants of sponge movement.

Time-lapse video definitively excluded the possibility that sponge movement resulted from directional growth. Moreover, if movement was mediated by growth, one would expect fed sponges to travel farther and at a higher speed than starved sponges. Our results, however, demonstrated the opposite. Indeed, our observations are consistent with the idea proposed by Bond \& Harris (1988) and Bond (1992) that sponges displace themselves by means of the individual amoeboid or crawling locomotion of the individual cells composing the basopinacoderm. Most cell types in sponges, if not all. are ahle to perform this cranling uctivity (Simpson 1984, Bond 1992). It is interesting that individuals of Scopalina lophyropoda left part of the basal skeleton behind as they moved along. This phenomenon has also been reported in other sponge species (Ankel 1967, Borojevic 1971, Bond \& Harris 1988). The latter authors observed that the moving individuals exert forces against these anchoring spicules. It is likely that the skeleton provides a support point to facilitate movement of those isolated cells or cell groups located in the inner part of the body. Otherwise, these cells would have no chance of coming into contact with a solid substratum, which is necessary for traction to be exerted. The role of the skeleton in facilitating the displacement of the bulk of soft tissue would explain why moving sponges are continuously secreting a new skeleton that is immediately left behind. It is worth noting that the continuous replacement of the skeleton may be a very costly process for siliceous sponges, since dissolved silica is probably a limiting resource in many sublittoral environments (Reincke \& Barthel 1997). We also observed how the internal system of canals was continuously reorganized as sponges moved at low speed, while little structure was found in the choanosome of individuals moving at high speed. A rapid tissue reorganization in moving sponges has also been reported by others (Borojevic 1971, Bond \& Harris 1988 , Bond 1992). Much of the ontogenetic change in body shape that has traditionally been considered as a passive response of the sponge to the environment may in fact be a result of processes of active displacement.

\section{Variation in movement responses}

Sponges were capable of modulating the intensity of the movement response over time. Two of the experiments in which we monitored sponges for 2 mo revealed that displacements were longer during the first month than during the second one. Moreover, the time effect on movement interacted with the effects of other factors, such as 'density of conspecifics' and 
'flow-silt' conditions. From a biological point of view, the interaction between 'time' and 'density of conspecifics' detected in the experiments suggests that a short, initial period of starvation does not induce a movement response in sponges, while settlement in a site surrounded by a high density of conspecifics is an undesirable initial situation that sponges somehow perceive and attempt to avoid by movement responses. However, if starvation is prolonged over time, it appears to become a powerful stimulus to locomotion and its effect overrides the potential effect that a highdensity of conspecifics would have on movement in a situation of regular food supply. Obviously, long-term starvation is more critical to survival than a long-term situation of high density of conspecifics. Nevertheless, both aspects may be related in the field, since intense competition for food may induce starvation of individuals in groups at high density. This appears not to be the case under the culture conditions of our experiment, because particulate food was at a high density and at no time during the experiment was it a limiting factor. Otherwise, the 'density of conspecifics' factor should have had a significant effect on the length of the path traced by sponges, or at least the interaction term between food and density factors should have been statistically significant.

The interaction detected between 'time' and 'flowsilt' factors in the other experiment reflects how the role of siltation in inducing sponge movernent decreased with increasing time. As the layer of silt was eliminated weekly from the aquarium bottom, we cannot discount the idea that, after a month of exposure to non-lethal silt levels, sponges somehow adapted themselves to tolerate a periodic, short-term burial and consequently the intensity of their movement response decreased.

Sponges also appear to be capable of alternating motion and resting periods, probably according to ecological demands. A long-term alternation between periods of motion and rest was evident by the marks resulting after bacterial colonization of paths traced by sponges after 7 mo in the cultures (Fig. 10C). A shortterm alternation between periods of motion and rest was characterized by the 'stop-and-reverse' movement behavior displayed by sponges in allogeneic encounters.

The variation in movement response over time and its interaction with other factors indicates that sponges are capable not only of perceiving a variety of environmental cues (e.g. food availability, exposure to silt, density of resident conspecifics), but also of elaborating a complex behavioral response. This is an unexpected capability in organisms that lack both sensory organs and a nervous system. Given the absence of sensory organs, the directionality of the sponge movement was predicted as being low. However, this pre- diction was not always confirmed in the experiments, since sponges performed oriented movements to avoid coming into contact with the experimental high-velocity water jets. Water flows are a cue that carry associated information concerning direction and are known to induce oriented movement responses in a large variety of animals (e.g. Young 1995). Isolated sponges placed in front of a neighboring barrier made of conspecifics also performed oriented displacements, moving preferentially towards barriers, irrespective of whether neighbors were isogeneic or allogeneic. This result suggests that sponges may somehow perceive the close occurrence (on a scale of $\mathrm{mm}$ ) of, at least. conspecifics and move in a direction that favors the encounter. However, sponges were unable to determine the sign of tissue compatibility until physical contact with neighbors was established.

\section{Ecological implications of sponge movement}

The results of our experiments suggest that the capability of locomotion has significant ecological implications for Scopalina lophyropoda. Both the intensity (i.e. net displacement) and the shape (i.e. straightness and directionality) of the movement responses were affected by the experimental conditions. Sponges traveled farther under adverse conditions, such as starvation and silt deposition, than under favorable conditions, such as a high availability of food and a lack of silt deposition. This type of response suggests that locomotion is part of a strategy for shifting to a better location when survival is threatened. It has previously been suggested that the locomotory capability might be used by sponges to readjust their position at the microhabitat scale and find new sites where survival was enhanced by reduced exposure to deleterious factors, such as light and silt (e.g. Wilkinson \& Vacelet 1979, Fishelson 1981). Our results are consistent with this idea and so are studies on some tunicates and bryozoans that have shown a noticeable capability of locomotion (e.g. Marcus 1926, Carlisle 1961, Birkeland et al. 1981, Ryland et al. 1984, Ryland 1988).

It is noteworthy that sponges consistently moved away from histoincompatible organisms once physical contact had been established. This behavior may be extremely advantageous, since histoincompatible individuals (either at the intra- or interspecific level) are potential competitors for food or space. Moreover, by avoiding prolonged contact with non-compatible individuals, sponges avoid the cost of immune rejection, a traumatic process characterized by intense cytotoxicity and cell killing (e.g. Hildemann et al. 1980, Hildemann \& Linthicum 1981, Johnston \& Hildemann 1983, Mukai \& Shimoda 1986, Smith 1988). Contact with incompati- 
ble neighbors followed by divergent movement may be a trial-and-error mechanism to explore the environment in the hope of locating a better site. We exclude the possibility that sponges are also accumulating immune information about their neighbors. Some experimental work has shown the existence of specific transplantation immunity or immune memory in a variety of sponge species, but this memory appears to persist no longer than $3 \mathrm{wk}$ after contact sensitization (e.g. Hildemann et al. 1979, 1980, Evans et al. 1980, Bigger et al. 1982, Smith \& Hildemann 1984). As Scopalina lophyropoda is not an aggressive cytotoxic species from a chemical point of view (Amade et al. 1987. Uriz et al. unpubl. data), the 'stop-and-reverse' movement behavior displayed by sponges in allogeneic encounters has to be interpreted as part of a defense mechanism for avoiding contact with competitors in the field. Nevertheless, locomotion may be used as an aggressive strategy by other sponge species, if combined with cytotoxicity effects. It has been shown, for example, how some moving didemnids (ascidians) can overgrow corals and move across the colony leaving behind a 'trail' of dying polyps and exposed coral skeleton (Birkeland et al. 1981). In this context, it has also been suggested that mobility in aggregated species may be a mechanism for smothering newly settled organisms before they have a chance to grow, therefore preserving the bare space created around the colonies, which can be used in periods of maximum growth and/or colony reproduction (Ryland et al. 1984).

Locomotion may also play an important role in processes of colony fission and reaggregation in many encrusting sponge species. Different parts of a modular colony may move at different rates or in different directions resulting in body fragmentation, as has been observed not only in sponges (Burton 1949, Bond \& Harris 1988, Pansini \& Pronzato 1990) but also in bryozoans (Marcus 1926) and ascidians (Birkeland et al. 1981, Ryland et al. 1984, Ryland 1988). Over several years, we have observed processes of fragmentation and partial reaggregation of large $\left(\sim 1 \mathrm{~m}^{2}\right)$ individuals of Scopalina lophyropoda in the field (pers. obs.). Repeated colony division and reaggregation would allow sponges to maintain an optimum ratio of periphery to area over time, a situation that may favor budding and asexual reproduction (e.g. Yamazato \& Isa 1982), enhance filtration in low energy situations (Bishop \& Bahr 1973), and facilitate survival on unconsolidated substrata in wave-exposed habitats (Ryland et al. 1984\}. It has been suggested that the most compelling explanation for the evolutionary acquisition of locomotion by sessile, modular organisms is that it not only makes possible colony fragmentation, but that it also facilitates a movement away from the fragmenting modules and subsequent mixing and fusion between non-clonal colonies, so that the resulting chimeric situation provides the most favorable conditions for crossfertilization (Harper 1977, Ryland et al. 1984). This is certainly not the case for $S$. lophyropoda, as virtually all encounters between non-clones were aborted by subsequent separation of the individuals involved. Moreover, although chimerism was formerly interpreted as a process that clearly led to an advantageous condition of the resulting chimeric individual (e.g. Buss 1982, Grosberg \& Quinn 1986, Rinkevich \& Weissman 1987), fusion with non-clones appears to be actively avoided in $S$. lophyropoda and other sponge and ascidian species, which suggests that the benefits of chimerims may not nverrome the costs in many caxco (e.g. Rinkevich \& Weissman 1992, Pancer et al. 1995, Maldonado 1998).

Reports by Burton (1949) and Wilkinson \& Vacelet (1979) on the movement of large sponges in the field are consistent with the result of our field experiment in supporting the idea that body size appears not to restrict significantly the capability of locomotion. We found no significant difference in the capability of locomotion of small and large individuals of Scopalina lophyropoda on the acetate substratum after a month in the field. This result suggests that the capability of young $S$. lophyropoda individuals to readjust their position in the habitat is not limited by body size during at least their first year in life. Indeed, the occurrence of locomotion in sponges, as well as in bryozoans and ascidians, forces us to reassess the universality of the assumption that larval choice for a settlement site is a critical event in organisms that are sessile as adults, because further relocation is impossible (e.g. Raimondi 1990). It appears that quite a few 'sessile' organisms can modify the course of post-settlement events not only by selective settlement or directional growth, but also by active locomotion across solid substrata in response to ecological demands.

Our results, along with those of previous studies, support that the capability of locomotion of some sponges, bryozoans and tunicates, although limited to short displacements, confers a number of significant advantages on these so-called sessile animals. Regardless of the mechanism, the ability to move influences the probability that individuals will experience physiological stress or encounter appropriate habitats, and this will have an effect on survival. It is clear that if these groups have evolved a capability of locomotion, then the selective (ecological) benefits derived from such an ability must overcome or at least balance histological and energetic costs (e.g. continuous skeleton replacement and aquiferous system reorganization).

Acknowledgements. We thank Dr Andrew R. David for providing thoughtful comments on an earlier version of the 
manuscript, Esther Benavente for help with fluorescence microscopy, Dr Xavier Turon for help with repeated-measures randomization analyses, Dr Enric Ballesteros for advice and help in photography, and Eva Bravo, $M^{\text {a }}$ Carmen Carmona, María Bardají and Ruth Martí for their support when field or laboratory tasks became overwhelming. Technicians at the Servicio de Microscopía de la Universidad de Barcelona are also thanked for their valuable help in processing material for TEM and SEM observation. This study was supported by a $M E C$ post-doctoral contract in connection with funds of a CE grant (MAS3CT97-0118) and a CICYT grant (MAR98-1004C02-01).

\section{LITERATURE CITED}

Amade P, Charroin C, Baby C, Vacelet J (1987) Antimicrobial activities of marine sponges from the Mediterranean Sea. Mar Biol 94:271-275

Ankel EF (1967) Ortsveränderungen von Süßwasserschwämmen unter dem Einfluß von Licht. Verh Dtsch Zool Ges 34: $395-401$

Batschelet E (1981) Circular statistic in biology. Academic Press, London

Battershill CN, Bergquist PR (1990) The influence of storms in asexual reproduction, recruitment, and survivorship of sponges. In: Rützler $K$ (ed) New perspectives in sponge biology. Smithsonian Institution Press, London, p 397-403

Bigger CH, Jokiel PL, Hildemann WH, Johnston IS (1982) Characterization of alloimmune memory in a sponge. $\mathrm{J}$ Immunol 129:1570-1572

Birkeland C, Cheng L, Lewin RA (1981) Motility of didemnid ascidian colonies. Bull Mar Sci 31:170-173

Bishop JW, Bahr LM (1973) Effects of colony size on feeding by Lophopodella carteri. In: Boardman RS, Cheetham AH, Oliver WA (eds) Animal colonies: development and function through time. Dowden, Hutchinson \& Ross, Stroudsburg, p 433-437

Bond C (1992) Continuous cell movements rearrange anatomical structures in intact sponges. J Exp Zool 263:284-302

Bond C. Harris AK (1988) Locomotion of sponges and its physical mechanism. J Exp Zool 246:271-284

Borojevic R (1971) Le comportement des cellules d'éponge lors de processus morphogénétiques. Ann Biol 10:533-545

Brusca RG, Brusca CJ (1990) Invertebrates. Sinauer Assoc Inc, Sunderland, MA

Burton M (1949) Observations on littoral sponges, including the supposed swarming of larvae, movement and coalescence in mature individuals, longevity and death. Proc Zool Soc Lond 118:893-905

Buss LW (1982) Somatic cell parasitism and the evolution of somatic tissue compatibility. Proc Natl Acad Sci USA 79: $5337-5341$

Buss LW (1990) Competition within and between encrusting cional invertebrates. Trends Ecol Evol 5:352-356

Carlisle DB (1961) Locomotory power of adult ascidians. Proc Zool Soc Lond 136:141-146

Davis AR, Targett NM, McConnell OJ, Young CM (1989) Epibiosis of marine algae and benthic invertebrates: natural products chemistry and other mechanisms inhibiting settlement and overgrowth. In: Scheuer PJ (ed) Bioorganic marine chemistry. Springer-Verlag, New York, p 85-114

Edmundson $\mathrm{CH}$ (1946) Reproduction in Donatia deformis (Thiele). Occas Pap Bernice P Bishop Mus, Honolulu 18: $271-282$

Emlen ST, Demong NJ (1978) Orientation strategies used by free-flying bird migrants: a radar tracking study. In:
Schmidt-Koening $\mathrm{K}$, Keeton WT (eds) Animal migration, navigation and homing. Springer-Verlag, Berlin, p 283-293

Evans CW, Kerr J, Curtis ASG (1980) Graft rejection and immune memory in marine sponges. In: Manning MJ (ed) Phylogeny of the immunological memory. Elsevier - North Holland, New York, p 27-34

Fishelson L (1981) Observations on the moving colonies of the genus Tethya (Demospongiae, Porifera). 1. Behaviour and cytology. Zoomorphology 98:89-99

Gosselin LA, Qian PY (1997) Juvenile mortality in benthic marine invertebrates. Mar Ecol Prog Ser 146:265-282

Grosberg RK, Quinn JF (1986) The genetic control and consequences of kin recognition by the larvae of a colonial marine invertebrate. Nature 322:456-459

Harper JL (1977) Population biology of plants. Academic Press, London

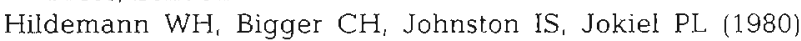
Characteristics of transplantation immunity in the sponge Callyspongia diffusa. Transplantation 30:362-367

Hildemann WH, Johnson I, Jokiel P (1979) Immunocompetence in the lowest metazoan phylum: transplantation immunity in sponges. Science 204:420-422

Hildemann WH, Linthicum DS (1981) Transplantation immunity in the Palau sponge, Xetospongia exigua. Transplantation 32:77-80

Hunt HL, Scheibling RE (1997) Role of early post-settlement mortality in recruitment of benthic marine invertebrates. Mar Ecol Prog Ser 155:269-301

Jackson JBC (1977) Competition on marine hard substrata: the adaptive significance of solitary and colonial strategies. Am Nat 111:743-767

Jackson JBC (1985) Distribution and ecology of clonal and aclonal benthic invertebrates. In: Jackson JBC, Buss LW, Cook RE (eds) Population biology and evolution of clonal organisms. Yale University Press, New Haven, p 297-355

Jackson JBC (1986) Modes of dispersal of clonal benthic invertebrates: consequences for species' distribution and genetic structure of local populations. Bull Mar Sci 39:588-606

Jandel Scientific Inc (1993) SigmaScan/Image. Measurement software. Jandel Scientific, San Rafael, CA

Johnston IS, Hildemann WH (1983) Morphological correlates of intraspecific grafting reactions in the marine demosponge Callyspongia diffusa. Mar Biol 74:25-33

Jokiel PL, Hildemann WH, Bigger CH (1982) Frequency of intercolony graft acceptance or rejection as a measure of population structure in the sponge Callyspongia diffusa. Mar Biol 71:135-139

Jones WC (1994) Process-formation by aquarium-kept sponges and its relevance to sponge ecology and taxonomy. In: Van Soest RWM, Van Kempen TMG, Braekman JC (eds) Sponges in time and space. AA Balkema, Rotterdam, p $241-250$

Maldonado M (1998) Do chimeric sponges have improved chances of survival? Mar Ecol Prog Ser 164:301-306

Maldonado M, Uriz MJ (1998) Microrefuge exploitation by subtidal encrusting sponges: patterns of settlement and post-settlement mortality. Mar Ecol Prog Ser 174:141-150

Maldonado M, Uriz MJ (1999) Sexual propagation by sponge fragments. Nature 398:476

Manly BFJ (1991) Randomization and Monte Carlo methods in biology. Chapman \& Hall, London

Marcus E (1926) Beobachtungen and Versuche an lebenden Süsswasserbryozoen. Zool Jahrb 52:279-350

Mardia KV (1972) Statistics of directional data. Academic Press, London

Meglitsch PA, Schram FR (1991) Invertebrate zoology. Oxford Univ Press, Oxford 
Milliken GA, Johnson DE (1984) Analysis of messy data: Vol 1. Designed experiments. Van Nostrand Reinhold, Co, New York

Mukai H, Shimoda H (1986) Studies on histocompatibility in natural populations of freshwater sponges. J Exp Zool 237 : 241-255

Neigel JE, Avise JC (1983) Histocompatibility bioassays of population structure in marine sponges. J Hered 74:134-140

Pancer Z, Gershon H, Rinkevich B (1995) Coexistence and possible parasitism of somatic and germ cell lines in chimeras of the colonial urochordate Botryllus schlosseri Biol Bull 189:106-112

Pansini M, Pronzato R (1990) Observations on the dynamics of a Mediterranean sponge community. In: Rützler K (ed) New perspectives in sponge biology. Smithsonian Institution Press, London, p 404-415

Paul V (1992) Chemical defenses of benthir marine invertebrates. In: Paul V (ed) Ecological roles of marine natural products. Comstock Publishing Associates, London

Pawlik JR (1993) Marine invertebrate chemical defenses. Chem Rev 93:1911-1922

Raimondi PT (1990) Patterns, mechanisms, consequences of variability in settlement and recruitment of an intertidal barnacle. Ecol Monogr 60:283-309

Reincke T, Barthel D (1997) Silica uptake kinetics of Halichondria panicea in Kiel Bight. Mar Biol 129:591-593

Rinkevich B, Weissman IL (1987) Chimeras in colonial invertebrates: a synergistic symbiosis or somatic- and germ-cell parasitism? Symbiosis 4:117-134

Rinkevich B, Weissman IL (1992) Chimeras vs genetically homogeneous individuals: potential fitness costs and benefits. Oikos 63:119-124

Ruppert EE, Barnes RD (1994) Zoology. Saunders College Publishing, New York

Ryland JS (1988) Ecology of movement in a reef ascidian, Diplosoma virens. Proc 6th Int Coral Reef Symp 3:361-366

Ryland JS, Wigley RA, Muirhead A (1984) Ecology and colonial dynamics of some Pacific reef flat Didemnidae (Ascidiacea). Zool J Linn Soc 80:261-282

Schmidt $O$ (1862) Die Spongien des Adriatischen Meeres. Engelmann W, Leipzig

Simpson TL (1984) The cell biology of sponges. SpringerVerlag, New York

Smith LC (1988) The role of mesohyl cells in sponge allograft rejections. In: Grosberg RK, Hedgecock D, Nelson RK (eds) Invertebrate historecognition. Plenum Press, New York, p 15-30

Editorial responsibility: Otto Kinne (Editor).

Oldendorf/Luhe, Germany
Smith LC, Hildemann WH (1984) Alloimmune memory is absent in Hymeniacidon sinapium, a marine sponge. J Immunol 133:2351-2355

Sokal RR, Rohlf FJ (1981) Biometry. Freeman WH, San Francisco

Spurr AR (1969) A low-viscosity resin embedding medium for electron microscopy. J Struct Res 26:31-43

Tsurumi M, Reiswig HM (1997) Sexual versus asexual reproduction in a oviparous rope-form sponge, Aplysina cauliformis (Porifera; Verongida). Invertebr Reprod Dev 32: $1-9$

Turon X, Tarjuelo I, Uriz MJ (1998) Growth dynamics and mortality of the encrusting sponge Crambe crambe (Poecilosclerida) in two contrasting habitats: correlation with population structure and investment in defence. Funct Ecol 12:631-639

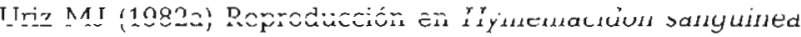
(Grant, 1926): biología de la larva primeros estadios postlarvarios. Invest Pesq 46:29-39

Uriz MJ (1982b) Morfología y comportamiento de la larva parenquímula de Scopalina lophyropoda Schmidt 1862 (Demospongiae, Halichondrida) y formación del rhagon. Invest Pesq 42:313-322

Uriz MJ, Maldonado M, Turon X, Martí R (1998) How do reproductive output, larval behaviour, and recruitment contribute to adult spatial patterns in Mediterranean encrusting sponges? Mar Ecol Prog Ser 167:137-148

Vaqué D (1996) Seasonal dynamics of planktonic microbial communities on the coastal northwest Mediterranean Sea. Publ Espec Inst Esp Oceanogr 22:39-46

Wilkinson CR, Vacelet $J$ (1979) Transplantation of marine sponges to different conditions of light and current. J Exp Mar Biol Ecol 37:91-104

Wulff JL (1985) Dispersal and survival of fragments of coral reef sponges. Proc 5th Int Coral Reef Symp 6:119-124

Wulff JL (1995) Effects of a hurricane on survival and orientation of large erect coral reef sponges. Coral Reefs 14: $55-61$

Yamazato K, Isa T (1982) Dynamics of colonial growth in a zoanthid, Palythoa tuberculosa (Esper). Proc 4th Coral Reef Symp 2:760

Young CM (1995) Behavior and locomotion during the dispersal phase of larval life. In: McEdward L (ed) Ecology of marine invertebrate larvae. CRC Press, Boca Raton, p 249-277

Zar JH (1984) Biostatistical analysis. Prentice-Hall, Englewood Cliffs, NJ

Submitted: November 24, 1998; Accepted: February 18, 1999 Proofs received from author(s): August 9, 1999 